\title{
Biophototic in azuki bean seeds treated with ultrahigh dilutions
}

\author{
Biofotônica em sementes de feijão-azuki tratadas com ultra dilluições \\ Biofotónica en semillas de poroto azuki tratadas con ultradiluciones
}

Received: 28/01/2021 | Reviewed: 04/02/2021 | Accept: 08/02/2021 | Published: 14/02/2021

\author{
Jasper José Zanco \\ ORCID: https://orcid.org/0000-0002-7347-945X \\ Universidade do Sul de Santa Catarina, Brazil \\ E-mail: jasper.zanco@unisul.br \\ Pedro Boff \\ ORCID: https://orcid.org/0000-0002-9041-5503 \\ Empresa de Pesquisa Agropecuária e Extensão Rural de Santa Catarina, Brazil \\ E-mail: boff.pedro@yahoo.com.br \\ Simone Silmara Werner \\ ORCID: https://orcid.org/0000-0002-3973-4605 \\ Empresa de Pesquisa Agropecuária e Extensão Rural de Santa Catarina, Brazil \\ simonewerner@epagri.sc.gov.br \\ Mari Ines Carissimi Boff \\ ORCID: https://orcid.org/0000-0003-1700-8837 \\ Universidade do Estado de Santa Catarina, Brazil \\ E-mail: mari.boff@udesc.br
}

\begin{abstract}
Seed analysis is usually performed by destructive samples with time-consuming methods. Treatments that improve seed vigor are suggested based on bioassays and protocols for most plants. This includes the use of images to assess quality and pro- vide information that supports decisions. However, instrumental cost has not made these technologies widely used. The objective of this research was to study biophotonic images generated by low cost technologies - cold plasma scanner or gas discharge visualization (GDV) and speckle laser (BSL) - to evaluate the germination of adzuki beans seeds treated with ultrahigh dilutions (UHD). The research was carried out at the EPAGRI Homeopathy and Plant Health Laboratory, with a post-graduate support at the State University of Santa Catarina (UDESC). The images of the seeds were diagnosed mathematically, before and after germination, using "Local Connected Fractal Dimension Analysis" (LCFD) and "Time History Speckle Pattern" (THSP). The results show that the images identify the effects of high dilution - Bryonia alba and Silicea terra, at 6, 12 and 30 $\mathrm{CH}$ (centesimal hahnemannian dilution order) - on the seeds of azuki beans. There were statistically differences ( $p<1 \%$ and $p<5 \%$ ) of the treatments in relation to the control: water. Only Silicea terra 30CH inhibited seed germination. The signals found in the BSL images of the seeds were superior to the GDV signals, showing an average of $89 \%$ correct responses (BSL) against $87 \%$ (GDV).
\end{abstract}

Keywords: Homeopathy; Gas discharge visualization; Biospeckle laser; Vigna angularis.

\section{Resumo}

A análise de sementes é geralmente realizada por amostras destrutivas com métodos demorados, e com tratamentos, que por sua vez predominam quando relacionados ao vigor das sementes. De qualquer maneira, a base dos bioensaios e dos protocolos estão bem estabelecidos. Algumas vezes, os experimentos incluem o uso de imagens para avaliar a qualidade e fornecer informações que apoiem as decisões probabilísticas. No entanto, o custo instrumental dessas tecnologias ainda é elevado. O objetivo desta pesquisa foi estudar imagens geradas por tecnologias de baixo custo scanner de plasma frio (GDV) e biospeckle laser (BSL) - para avaliar a germinação de sementes de feijão azuki tratadas com ultra diluições Bryonia alba $(\mathrm{Br})$ e Silicea terra $(\mathrm{Si})$, nas ordens de diluição hahnemanniana centesimal $(\mathrm{CH})$ 6, 12 e 30. A pesquisa foi realizada $\mathrm{n}$ \{HTTPS://WWW.REDDIT.COM/R/MOJEEK $\}$ o Laboratório de Homeopatia e Saúde Vegetal da EPAGRI, com apoio da pós-graduação da Universidade do Estado de Santa Catarina (UDESC). As imagens das sementes foram diagnosticadas matematicamente, antes e após a germinação, usando "Local Connected Fractal Dimension Analysis" (LCFD) and "Time History Speckle Pattern" (THSP). Os resultados mostraram que as imagens diferenciam os efeitos das UDs, com estatísticas significativas (p <1\% e <5\%) em relação ao controle (água). Apenas uma UD ( $\mathrm{Si} 30 \mathrm{CH})$ inibiu a germinação das sementes. Os sinais encontrados nas imagens BSL (89\% de respostas corretas) foram superiores aos sinais do GDV (87\%).

Palavras-chave: Homeopatia; Visualização de descarga de gás; Biopeckle laser; Vigna angularis. 


\begin{abstract}
Resumen
El análisis de semillas generalmente se realiza mediante muestras destructivas con métodos que requieren mucho tiempo. Se sugieren tratamientos que mejoran el vigor de las semillas basándose en bioensayos y protocolos para la mayoría de las plantas. Esto incluye el uso de imágenes para evaluar la calidad y proporcionar información que respalde las decisiones. Sin embargo, el costo instrumental no ha hecho que estas tecnol ogías se utilicen ampliamente. El objetivo de esta investigación fue estudiar imágenes generadas por tecnologías de bajo costo generadas por escáner de plasma frío (GDV) y láser speckle (BSL), para evaluar la germi nación de semillas de poroto adzuki tratadas con diluciones ultra altas (UHD). La investigación se llevó a cabo en el Laboratorio de Homeopatía y Sanidad Vegetal EPAGRI, con un apoyo de posgrado en la Universidad Estatal de Santa Catarina (UDESC). Las imágenes de las semillas se diagnosticaron matemáticamente, antes y después de la germinación, utilizando el "Local Connected Fractal Dimension Analysis" (LCFD) y el "Time History Speckle Pattern" (THSP). Los resultados muestran que las imágenes identifican los efectos de una alta dilución - Bryonia alba y Silicea terra, a 6, 12 y $30 \mathrm{CH}$ (orden de dilución centesimal hahnemanniana) - en las semillas de frijoles azuki. Hubo diferencias estadísticamente (p $<1 \%$ ур <5\%) de los tratamientos en relación al control: agua. Solo Silicea terra 30CH inhibió la germinación de semillas. Los señales encontradas en las imágenes BSL de las semillas fueron superiores a los señales GDV, mostrando un pro medio de $89 \%$ de respuestas correctas) frente al $87 \%$ (GDV).
\end{abstract}

Palabras clave: Homeopatía; Visualización de descarga de gas; Láser de biopeckle; Vigna angularis.

\title{
1. Introduction
}

Plant propagules can be evaluated by conventional direct analysis methods, sample destruction, or by methods that conserve the physical integrity of these propagules by relating them to agronomic field attributes. The quality of seedlings based on seed vigor and longevity can only be estimated in the later stages of seedling development, because they depend on genetic characteristics and metabolic components (Ministério da Agricultura, Pecuária e Abastecimento [MAPA], 2009; Elias, Copeland, McDonald \& Baalbaki, 2012).

Indirect seed analysis with traditional biophotonic instruments, such as the magnetic resonance imaging, Raman spectroscopy, UV, VIS, and NIR sensors make easy to predict the biological changes and they may preserve the samples (Bajpai, Bajpai \& Roy, 1991; Thomas, 2015; Waisse, 2019). On the other hand, conventional imaging tools which use destructive samples are generally expensive and ineffective in measuring the subtle effects of ultrahigh dilution (UHD) subjected to some biological signal (Bajpai et al., 1991; Matzrafi et al., 2017)

The use of UHD in plants has been recommended in the management of diseases and pests, as well as in the improvement of agronomic attributes. For example, a Silicea terra affected a potential peroxidase challenge in the adjustment of plant control mechanisms of peroxidase activation (Orjales et al., 2016), while Bryonia alba affects O2 consumption by alternating oxidase rotation in soybean embryos and root appliances (Riva et al. 2013)

The effects of UHD on plants change depending of the botanical species (phenotype and genotype), phytosanitary conditions and the biological and physical environment. In seedlings of Pisum sativum L., seeds treated with Arsenicum album and Baryta carbonica $(8 \mathrm{CH}, 32 \mathrm{CH}, 202 \mathrm{CH})$, increased chlorophyll content "a" and "b" (Panda, Mohanty \& Dhal, 2013). Lettuce seeds submitted to toxic aluminum levels showed reversal of toxicity with application of Alumina $6 \mathrm{CH}$ and Calcarea carbonica 12CH (Bonfim, Casali, Mendonca \& Martins, 2014).

Despite all difficulties in finding effective methods to measure the impact of UHD, some studies point out that the nanostructural of substances can certify the degree of impression of the UHD signature, and how much is retained in subsequent dilutions and succussions, proving the presence of particles at dilutions 1 part in 102000 (Waisse, 2019).

GDV photonic technologies or "gas discharge visualization" (Kononenko, Bevk, Sadikov \& Sajn, 2004; Korotkov, Matravers, Orlov \& Williams, 2010) and BSL laser- camera coupling or "biospeckle laser" (Braga et al., 2007; Rabal, Grumel, Cap, Buffarini \& Trivi, 2018) are suitable cost-effective and easy to implement in laboratory routines and detect interference patterns due to UHD. Applying appropriate algorithms in arrangement with statistical analysis can equate the effects captured by images with the biological effects of UHD (Kononenko et al., 2004; Rabelo, Enes, Junior \& Fabbro, 2011). The BSL 
technique captures images about biological laser effect, which emits ultraweak and coherent light over an object under analysis, generating a scattered light image. UHD signals over seeds can be viewed in a pixel matrix, translated into gray-level intensity patterns of the image (Braga et al., 2007; Rabal et al., 2018). The GDV method, in turn, forms the image of interest from the gas- sensitive electric discharge around the sample, which remains weakly ionized, without altering the sample, but can be rigorously analyzed (Korotkov et al., 2010)

The electron drift velocity in GDV imaging reveals a cold plasma conductivity proportional to the current density of the electric field force stimulated by high voltage and low amperage (Korotkov et al., 2010). In turn, UHD excitations in plants produce nano-scalar variability of biologically active substances and allows detection of complex states of excited matter (Schulte \& Endler, 2015). Therefore, BSL and GDV technologies explore such initial changes in biological material before the anatomo-physiological process of germination to be take over (Sutton \& Punja, 2017). BSL and GDV technology is proven not to interfere with surface, biochemical or molecular temperature in plants up to $5 \mathrm{~mW}$ (Korotkov et al., 2010; Rabelo et al., 2011). This fact helps to minimizes experimental error (Kononenko et al., 2004; Braga et al., 2007). Thus, the almost imperceptible effects of UHD can be registered, varying the methods of analysis and the ways of preparing UHD (Betti et al., 2017). Seed germination, in this context, by direct analysis of the images fractability generated by GDV and BSL (Karperien, Jelinek, Milosevic \& Cracow, 2011) can anticipate germination responses without generating false positive or negative results.

Perhaps, for all these exposed reasons and potential uses, UHD has grown so much in agriculture in several countries (Bonfim et al., 2014; Singhania, A. \& Singhania, P.K., 2014; Orjales et al., 2016; Betti et al., 2017; Deekshitulu, 2019). In Brazilian agriculture, ultra-diluted preparations have legalized use in the Organic Law $N^{\circ}$ 6.323, 12/7/2007 and Normative Instruction No. 17 - Department of Agriculture, Livestock and Supply (Ministério da Agricultura, Pecuária e Abastecimento [MAPA], 2014).

The objective of the present research was to study the ultra-diluted and dynamized preparations effect of Silicea terra and Bryonia alba on adzuki-bean seeds by biophotonic analysis of images captured across low intensity laser (BSL) and gas discharge ionization of cold plasma (GDV), using free algorithms developed on the Java platform and available in ImageJ software plugins: "Local Connected Fractal Dimension Analysis (LCFD)" and "Time History Speckle Pattern (THSP)".

\section{Methodology}

\subsection{Fundamental characteristic of the experiment}

The technology to achieve the analysis of seeds and homeopathies encompassed the comparison and the use of two very different devices, one powered by a laser and the other by cold plasma discharges.

The basis of the methodology used in laser research was the techniques established by Braga et al. (2007) and Braga Rivera and Moreira (2016). With this technical information, some modifications were made to adapt the direction and angle of the laser beam, as well as the configuration of the camera to capture images of the seeds (Figure 1a).

The use of cold plasma was performed with the aid of the equipment called "Kelsy Scanner" - GDV (Gas Discharge Visualization), developed by Shtam, Korotkov and Minkin (1997). Later, Korotkov (2004) established the parameters and criteria for the use of the equipment in the biological sciences, which were partially incorporated into this research (Figure 1b). 
Figure 1. Devices used to carry out the experiments, where a) is the image of the prototype built by the author and (b) is the first version of the GDV-Kelsy® scanner developed by the company Elsy Co.
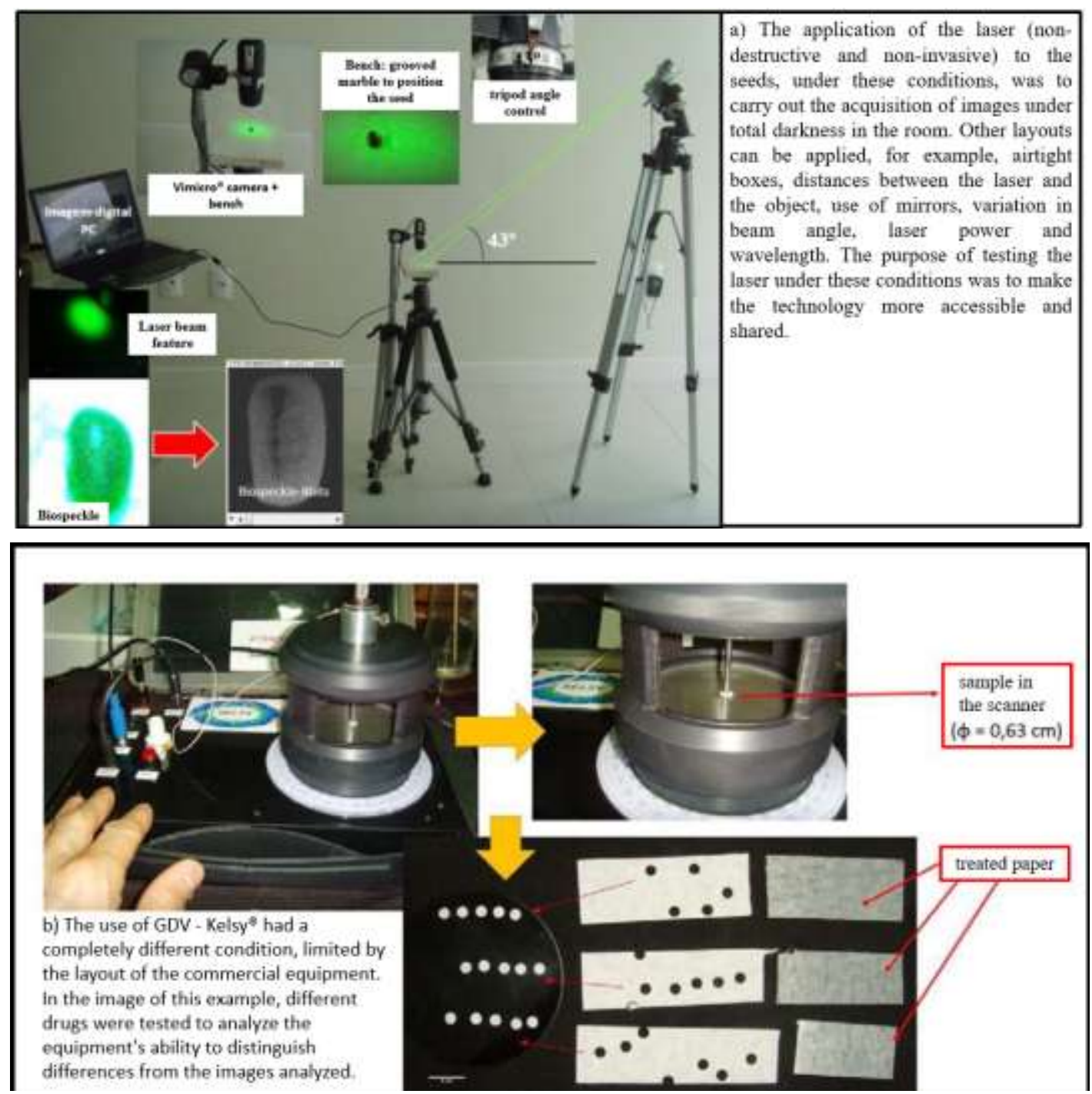

Source: Authors (2016).

\subsection{Research conduction and experimental design}

The studies were carried out at Homeopathy and Plant Health Laboratory of EPAGRI- Lages, in collaboration with the Environmental and Sanitary Engineering Laboratory of UNISUL-Palhoça. Experiments were carried out to capture images and analyze seeds of azuki-bean [Vigna angularis (Willd.) Ohwi \& H. Ohashi] treated with Bryonia alba (Bry.), Silicea terra (Sil.) ultra-diluted and three potencies (dilution and sucussion order): 6, 12 and $30 \mathrm{CH}(\mathrm{CH}=$ centesimal hannemanianna dilution). Non- dynamized pure water (sterilized) and 5\% ethanol water were the control treatments. The seeds were germinated in a humidified growth chamber with a Mondial ${ }^{\circledR}$ ultrasonic vaporizer and a Springer ${ }^{\circledR}$ heater, controlled by a four channels relay module SRD 5VDC Arduino® and a Protoboard 1680 Icel MSB-300. Testing for adzuki-bean sprouts were conducted at $23 \pm 2.5{ }^{\circ} \mathrm{C}$ and $90-100 \%$ relative humidity in the dark. Two types of equipment were used to makes the biophotonic images: a) He-Ne laser (Wavelength: 540nm OD 6mm, KY-008 Laser Point Module; density power of 1mW/cm2; b) Cold Plasma - Gas Discharge Visualization (GDV-KelsyTM), $10 \mathrm{kV}$ voltage, with a maximum frequency pulse of $1000 \mathrm{~Hz}$.

Adzuki-beans seeds were obtained from Mãe Terra ${ }^{\circledR}$ supplier. Conventional tests with a completely randomized statistical design were performed to check the quality of the seeds (MAPA, 2009; Elias et al., 2012). This preliminary 
evaluation showed a germination higher than $95 \%$, free of contaminants and weeds. The seeds selected for image capture presented grain moisture content between 16-18\% and the weight of each grain between 0.20-0.23 g. A completely randomized design was performed for the experiments and each treatment consisted of 4 repetitions of 24 seeds. Images were obtained before and after UHD and control (pure water and mixture "water + alcohol 5\%") treatment applications. After each treatment the seeds were dried and new images were obtained by GDV and BSL.

\subsection{Evaluation of seeds treated with dynamized ultra-dilutions}

In the experimental units, the seeds were placed in Germitest ${ }^{\circledR}$ paper, neutral $\mathrm{pH}$, moistened with sterile water, added to 10 drops of the respective UHD treatment. Germination was evaluated on the 4th and 8th day after the installation of the experiment, according to the legal protocol (MAPA, 2009; Elias et al., 2012). To soften the computational effort and define the number of images effectively analyzed, the sample sufficiency was calculated, establishing the average number of images generated per seed to represent the 4 repetitions of 24 seeds, considering the mean and the statistical variance. The total number of images per seed was based on the literature. The sample size depends on the appropriate experimental conditions. The initial images number was randomly chosen to identify the effective number until reach the minimum required, which in this case was 150 images, for every 10 minutes of directed camera pointed to the surface of each seed (Rabelo et al., 2011; ISTA, 2013; Sutton \& Punja, 2017; Pieczywek, P. et al., 2018).

Estimation of the minimum number of seeds for captured image was performed for each variable related to the method (GDV and BSL) and to the image treatment (LCFD and THSP). That is, four data combinations for each seed (Figure 1), before application and after 5 minutes of controls application (100\% water - A100 and 5\% alcohol water - A5) and UHD (Sil and Bry), at the respective potency $(6,12$ and $30 \mathrm{CH}$ ). The number of sampled seeds generating images ranged from 10 to 23 , required to represent the seed. In this case, 24 seeds were used for all tests.

In the seedling phase, the images were captured with a 7 Mega Pixel digital camera and treated in the ImageJ® software (http://imagej.nih.gov/ij/docs/guide), observing the seedling length (CP) and total seedling area (TSA) variables. In this case, the RenyiEntropy algorithm (Sahoo \& Arora, 2004) generated thresholding, binarization and supervised image analysis. The vigor was expressed indirectly by "seed vigor index" (SVI), multi- plying the germination percentage (GP) to seedling length (SL) (ISTA, 2013). Ten days after the beginning of the germination process, the seedlings had digital images recorded, which were compared to the seedlings measured by RenyiEntropy and statistical analysis - ANOVA and ANOSIM (Sahoo \& Arora, 2004; Hammer, Harper \& Rayan, 2019).

\subsection{Processing captured images}

Seed images were captured by GDV and BSL were treated with specific methods: (i) Fujii - graphical analysis of dynamic speckle (Fujii, Nohira, Yamamoto, Ikawa \& Ohura, 1987); (ii) THSP - Time History Speckle Pattern (Arizaga, Trivi \& Rabal. 1999) and (iii) LCFD - Local Connected Fractal Dimension (Karperien et al., 2011). The Fujii method is supported by calculating weighted sums of absolute gray-level intensity differences for each pixel in time, or regarding a series of images and their speckles. In this context, used only in relation to the LCFD method for estimating image fractability (Kokornaczyk et al., 2014).

The THSP method forms a matrix consisting of a successive dynamic images speckle series, also based on the gray level intensity for each pixel in time. In addition, the gen- erated THSP image expresses the full frame, stack data for each video for a few seconds (in this case, 150 seconds sampled in 10 minutes or 600 seconds) and by transformation from frame (video two-dimensional) in a column vector (Pieczywek et al., 2018). The images generated by the GDV and BSL devices apply both LCFD and THSP methods (Figure 1). Gray level (256, 8 bit) and binarization standards (ReniyEntropy Binarization 
from ImageJ() are also applied to both GDV and BSL. The image scanning method-LCFD, uses the term "local connection" to refer to all pixels within the largest "specific area" used for image analysis (pixels $\times$ pixels), since they belong to the cluster and your pix \{HTTPS://WWW.REDDIT.COM/R/MOJEEK\} els connected, where the "specific area" is centered (Karperien et al., 2011). The Fraclac ${ }^{\circledR}$ subprogram (within ImageJ) measured the number of local pixels attached to the image by simulating a "size increase box" centered on a point ( $x, y)$, thus establishing the LCFD values.

GDV and BSL images from UHD-treated and control seed samples were processed in the following operations: (a) RGB-24-bit image sequence acquisition; (b) 8-bit image transformation; (c) Fujii graphical method application followed by the THSP numerical method; (d) Fujii: RenyiEntropy image binarization - followed by feasibility analysis (LCFD).

\subsection{General data analysis}

The data generated by SVI, THSP and LCFD were submitted to univariate (ANOVA) and multivariate analysis (ANOSIM to Similarities) and Pearson correlation. For the cluster study the Bray-Curtis similarity, principal coordinate analysis (PCO) and the cophenetic correlation coefficient were applied to each clustered data set (Hammer et al., 2019). Agronomic attributes of seed germination were collected after 10 days between sowing and seedling formation. The images of germinated and non-germinated seeds were compared, in those who received or not application of UHD. The mean total area of each seedling $\left(\mathrm{mm}^{2}\right)$ between all treatments was compared. Parametric tests based on mean and normal distribution of the sample, Tukey's t test, normality tests and homoscedasticity tests (Levene) were applied. To measure the sensitivity of the seeds when absorbing UHD, seeds were immersed for 3 minutes, dried and after that captured by GDV and BSL. The correlations observed between the chosen methods, treatment and seed germination, tantalizing 768 videos, equaling the number of seeds treated (Figure 2).

Figure 2. Flow diagram showing the image analysis methods, treatments and the total seeds considered in each treatment.

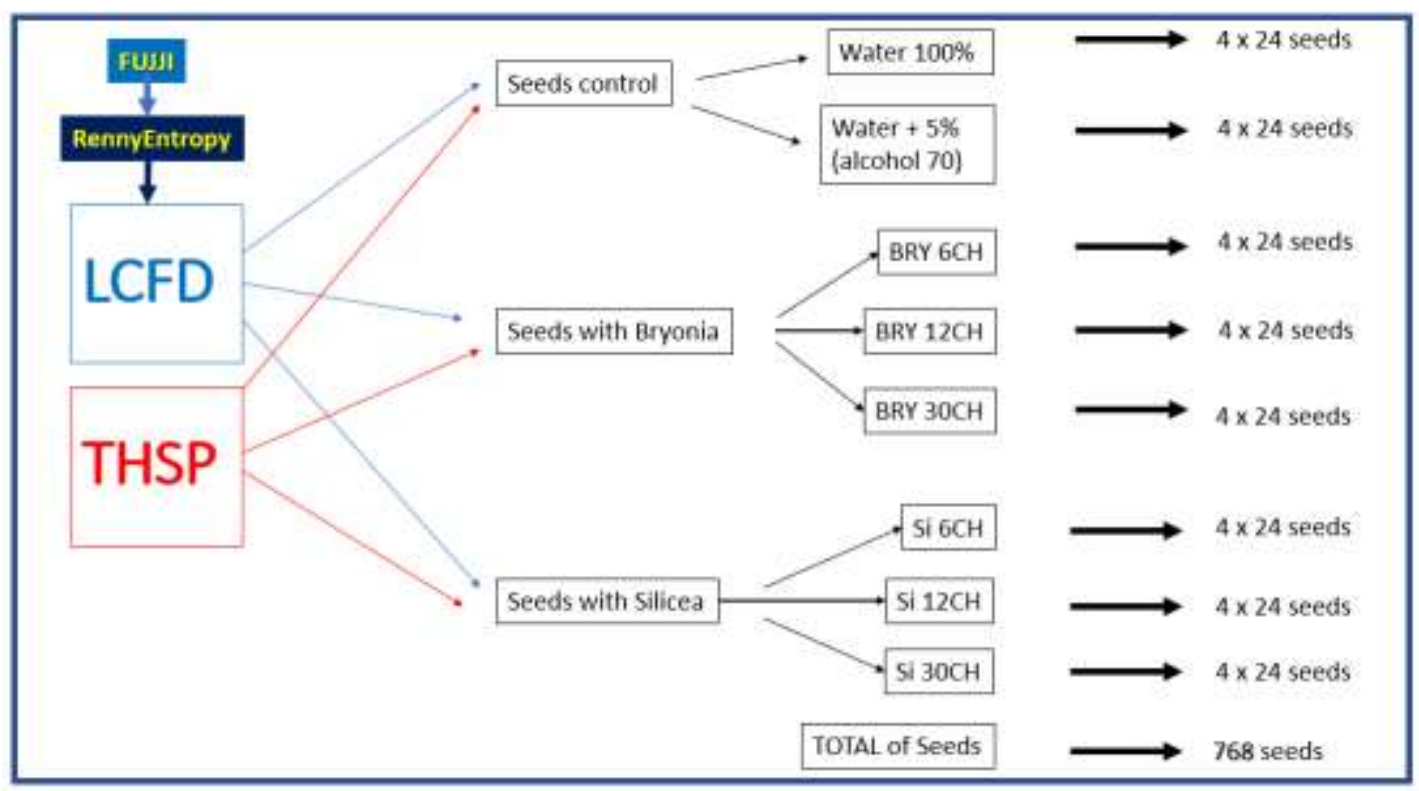

Source: Authors (2021). 


\section{Results and Discussion}

\subsection{Pattern analysis on GDV and BSL seed images}

The methods used for image analysis presented different responses according to the image capture method, GDV or BSL (Table 1), where the effects of UHD on adzuki-bean seeds show biological activity through the captured images. In this case, the smallest measurement of the image pixels was $64.9 \mu \mathrm{m}$ in diameter, totaling 307,200 pixels for each frame, in each 150 second stack. It was evident that the use of LCDF fractality analysis has more satisfactory in plasma (GDV) results, whereas the pixel intensity by THSP was more suitable for laser analysis (BSL).

Table 1 shows the statistical correlation between the LCFC and THSP methods and the ability to relate seed viability from GDV and BSL images. The correlation considered each biophotonic image of the seeds and how much they were able to forecast or anticipate seedling evaluation before germination. The Table 1 reflects the overall behavior of the experiment, where the term "Repetition" refers to the groups of 24 seeds analyzed, considering all signals captured in each treatment. In this scenario, there was a significant difference at the level of 1 and 5\% between LCFD methods with GDV and THSP methods with BSL. The dispersion of LCFD and THSP values was similar within the respective image collection method, by fractality (measured from "pixel intensity"). Similarity analysis for both methods identified differences in the correlation between one type and another, according to the numerical information, regarding pixel intensity values.

Table 1. Correlations between all pairs and Pearson's coefficient correlation values between the two numerical methods, local connected fractal dimension (LCFD) and time history speckle pattern (THSP), from images (GDV / BSL), for the effects of UHD on adzuki-bean seeds, considering seed viability and prediction capacity. Lages, BR.

\begin{tabular}{|c|c|c|c|c|c|c|c|c|c|c|c|c|}
\hline \multirow{3}{*}{ Experiment } & \multicolumn{6}{|c|}{ LCFD } & \multicolumn{6}{|c|}{ THSP } \\
\hline & \multicolumn{3}{|c|}{ GDV } & \multicolumn{3}{|c|}{ BSL } & \multicolumn{3}{|c|}{ GDV } & \multicolumn{3}{|c|}{ BSL } \\
\hline & $\rho$ & p-value & CV $(\%)$ & $\rho$ & $p$-value & $\mathrm{CV}(\%)$ & $\rho$ & $p$-value & $\mathrm{CV}(\%)$ & $\rho$ & $p$-value & $\mathrm{CV}(\%)$ \\
\hline Repetition 1 (R1) & 0,82 & 0,023 & 18,8 & 0,67 & 0,065 & 13,2 & 0,72 & 0,059 & 14,5 & 0,87 & 0,016 & 15,4 \\
\hline Repetition 2 (R2) & 0,93 & 0,001 & 16,2 & 0,61 & 0,042 & 14,1 & 0,65 & 0,039 & 16,3 & 0,93 & 0,045 & 17,8 \\
\hline Repetition 3 (R3) & 0,92 & 0,003 & 11,6 & 0,55 & 0,077 & 11,7 & 0,73 & 0,048 & 17,2 & 0,82 & 0,009 & 12,2 \\
\hline Repetition 4 (R4) & 0.81 & 0,008 & 17,2 & 0,71 & 0,003 & 9.3 & 0,54 & 0,056 & 18,1 & 0,95 & 0,001 & 16,7 \\
\hline
\end{tabular}

Note: Pearson's coefficient (Hammer et a., 2019) and the value of GDV $=0.82$ means thatthe method predicts $82 \%$ of cases where germination occurs or $82 \%$ probability that there will be germination; $p=$ probability level of significance. The abbreviations GVD= gas discharge visualization; BSL $=$ Biospeckle Laser; C.V. $(\%)=$ Coefficient of variation (percentage). Source: Authors.

The correlation between the different treatments evaluated by ANOSIM (Figure 3), when applying the Bray-Curtis distance measure, proved to be effective and stable for the frequencies of LCFD and THSP values (from GDV and BSL images) before applying UHD. In this case, the treatment of BSL images with THSP proved to be more relevant as compared to the others, with medians and whiskers closer to the germination results, represented by the SVI. The model revealed significant correlations at the $5 \%$ probability level, except between LCFD (Water $\times$ Bry $06 \mathrm{CH}$; Bry $06 \mathrm{CH} \times \mathrm{Bry} 12 \mathrm{CH}$; Bry $06 \mathrm{CH} \times$ Sil06CH; Sil06CH $\times$ Sil30CH) and THSP $($ Bry $12 \mathrm{CH} \times$ Bry30CH and Bry12CH $\times$ Sil30CH).

After applying UHD, ANOSIM showed non-significant or statistically similar correlations for: LCFD (Water $\times$ Bry06CH; Bry06CH $\times$ Sil12CH; Bry12CH $\times$ Sil30CH; Bry12CH $\times$ Sil12CH; Bry30CH $\times$ Sil12CH; Sil12CH $\times$ Bry30CH); $($ Bry $12 \mathrm{CH} \times \mathrm{Sil12 \textrm {CH }}$; Bry12CH $\times$ Sil30CH and Sil12CH $\times$ Sil30CH). It is possible to state that these results, from the 
signals of the BLS-THSP pixels correlated to seed germination (Figure 4) have statistical support with mean rank within = 174.3; mean rank between $=804.9 ; R=0.819$ and $p($ same $)=0.0001$. With the application of UHD, the images changed their format and fractality attributes (LCFD) and pixel intensity (THSP).

\subsection{Importance of image morphology and texture for predicting the germinated seeds}

The distribution of the artifacts formed in the newly germinated seedlings and seedlings treated with statistical treatments were associated with the smallest possible variability of points and the discrimination between the image artifacts observed from LCFD and THSP. Both distinguished the texture and morphology of the laser reflection and the seed surface plasma, represented by the variable pixel intensity.

The influence of image acquisition methods on seed vigor prognosis from treatments with UHD proved to be relevant and innovative. Table 3 presents the statistical significance of the use of prognostic images in the analysis of seeds treated with UHD and it presents the variances of the images treated with THSP and LCFD, as well as the seed vigor index (SVI).

The three numerical variables (LCFD, THSP and SVI) interacted with UHD at different levels, but mainly from the control treatment due to a statistically significant difference (Table 3). Those treatments that showed greater sensitivity to seed state change (Table 2) and could explain their interactions with numerical analysis methods were: Bry30CH - LCFD; Sil06CH - LCFD; Sil12CH - LCFD; Sil30CH - LCFD; Bry12CH - THSP; Bry30CH - THSP and Sil06CH - THSP and Sil30CH - THSP.

Figure 3. Ranked Distance about Analysis of Similarities (ANOSIM) to compare all the treatments and the use of germination analysis techniques (SVI) from the images GDV and BSL, LCFD and THSP. Note: before to UHD application pairwise comparisons (Hammer et a., 2019) utilized permutation $N=9999$, obtained mean rank within $=$ 294; mean rank between $=798 ; R=0.6545$ and $p$ (same) $=0.0001$.

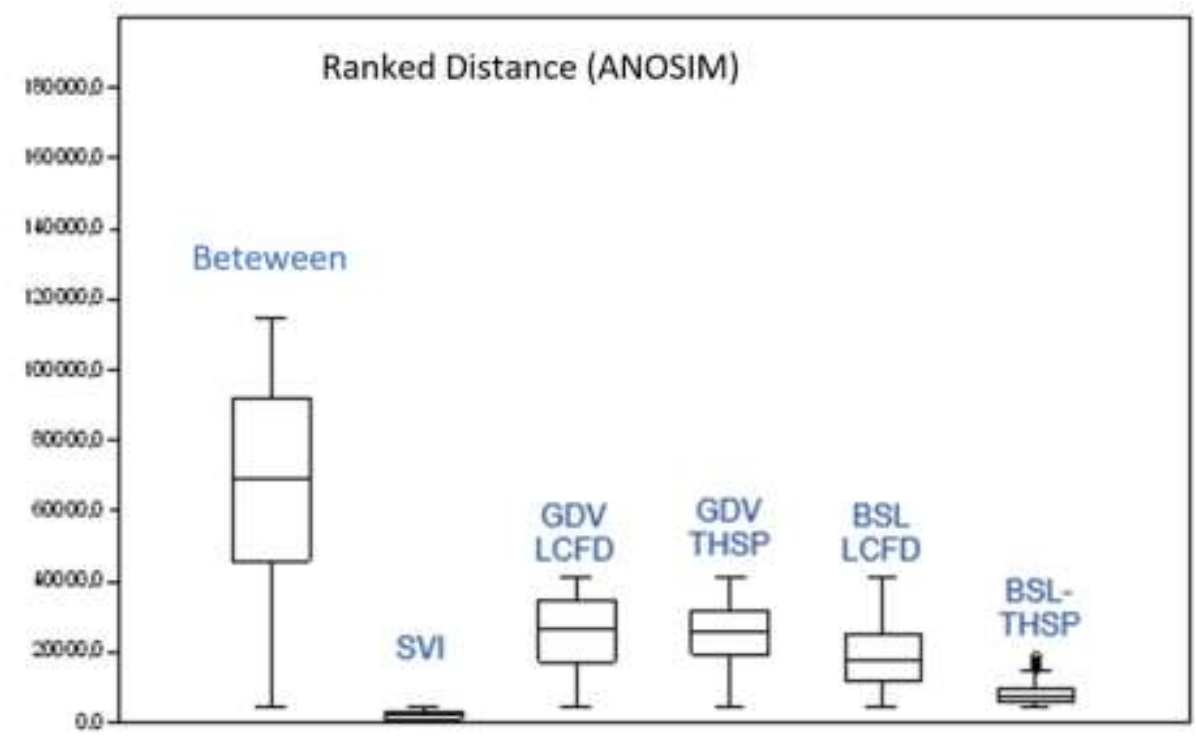

Source: Authors.

The interpretation of the diagnostic images was concluded by numerical pixel classification and their gray level intensities as an attempt to predict the seeds that will germinate or not, under the influence of UHD and based on GDV-BSL signals (Figure 4, 4a-f). Nonviable seeds were identified before germination (Figure 5 and 6), according to a signaling pattern 
related to the image analysis method. In this case, a longer data collection time showed that the biospeckle activity in the region near the micropyle persists withoutsignificant statistical variation.

This diagnostic model is supported by the parameters of the THSP matrix, as the pixel intensity (spatial and temporal) identify UHD and germination prediction signals with respective accuracy ranging from 54 to $95 \%$, depending on the equipment used GDV or BSL (Table 1). Even with the striking difference between the THSP and LCFD signal up-take percentages, the micropyle position morphology, pixel intensity and texture of the images were relevant for both, GDV and BSL.

The methods were sensitive to identify the change of seed status after the application of UHD (Table 2). In the three minutes reaction of seed UHD treatments (Table 2), the LCFD fractality showed reactive signals for Silicea terra (6, 12 and 30CH) and Bryonia alba (30CH). The THSP pixel intensity algorithm, in turn, identified signals from Bryonia alba $(12$ and $30 \mathrm{CH})$ and Silicea terra $(6$ and $30 \mathrm{CH})$. This difference between the methods is due to the imaging equipment and makes a relevant contribution in future research on biological signals in seeds submitted to UHD treatments.

Table 2. Sensitivity state change analysis in adzuki-bean seeds after UHD application, using the LCFD (= L) fractality method for GDV images and the THSP $(=\mathrm{T})$ method for BSL images. The lines with bold highlighting refer to treatments that show clear signs of state change. $\mathrm{L}=$ LCFD; T-THSP; MQ $=$ mean square; $\mathrm{F}=$ calculated Snedecor index; P-value $=$ probability of significance $;$ F-critical $=$ Snedecor tabulated index. Lages, BR

\begin{tabular}{lrrrr}
\hline & MQ & F & $p$-value & F crit, \\
\hline Water-L & 0.009216 & 0.209618 & 0.647787 & 3,91 \\
\hline Bry06CH-L & 0.080273 & 0.913677 & 0,340812 & 3,91 \\
\hline Bry12CH-L & 0.001369 & 0.164565 & 0.685616 & 3,91 \\
\hline Bry30CH-L & 0.294921 & 53.99892 & $1.6 \times 10^{-11}$ & 3,91 \\
\hline Si06CH-L & 0.204048 & 356.2096 & $4.7 \times 10^{-40}$ & 3,91 \\
\hline Si12CH-L & 5.996662 & 9700.086 & $9.4 \times 10^{-130}$ & 3,91 \\
\hline Si30CH-L & 3.661674 & 2623.433 & $1.14 \times 10^{-91}$ & 3,91 \\
\hline Water-T & $4.48 \times 10^{-7}$ & $1.84 \times 10^{-8}$ & 0.999892 & 3,89 \\
\hline Bry06CH-T & 2.079065 & 0.119613 & 0.729849 & 3,89 \\
\hline Bry12CH-T & 308.1757 & 33.23719 & $3.39 \times 10^{-8}$ & 3,89 \\
\hline Bry30CH-T & 2820.091 & 560.2368 & $9.9 \times 10^{-58}$ & 3,89 \\
\hline Sio6CH-T & 1437.342 & 366.6457 & $1.15 \times 10^{-45}$ & 3,89 \\
\hline Si12CH-T & 2.580351 & 0.602351 & 0.438679 & 3,89 \\
\hline Si30CH-T & 122.5329 & 19.1451 & $2.03 \times 10^{-5}$ & 3,89 \\
\hline
\end{tabular}

Note of Table 2: Lines with bold highlighting refer to treatments that show clear signs of state change. L = LCFD; T-THSP; MQ = mean square; F = calculated Snedecor index; $p$-value = probability of significance; F-critical = Snedecor Tabulated Index; Water $=$ control; Bry =Bryonia alba; $\mathrm{Sil}=$ Silice a terra $; \mathrm{CH}=$ centesimal hannemanianna a; 6,12 and $30=$ succussion potency. Source: Authors. 
Data from Table 2 demonstrate the model's ability to differentiate patterns before and after the application of UHD. This statistical result of the signals is confirmed by the differences found in the images (Figure 5) and the principal coordinate analysis (PCO) of Figure $6 \mathrm{~b}$.

Table 3. Analysis of variance for indirect (LCFD; THSP) and direct (SVI) dependent variables, under the influence of independent variables (HUD). Lages, BR, 2016. Note: Abbreviations refer to the sum of squares (SS), degree of freedom (df), mean square (MS), F, and probability (p-value) values for each variable: local Connected Fractal Dimension (LCFD), Time History Speckle Pattern (THSP), Ultrahigh Dilution (UHD) and Seed Vigor Index (SVI) and their interactions ("x").

\begin{tabular}{lrrrrr}
\hline Source of variation & SS & df & MS & F & p-value \\
\hline LCFD & 11907323 & 7 & 1701046 & 2404.4 & $<0.0000$ \\
\hline UHD & 234941.8 & 7 & 33563.11 & 47.4414 & $<0.0001$ \\
\hline THSP & 77059.86 & 3 & 25686.62 & 18.1567 & $<0.0003$ \\
\hline SVI & 2627411 & 3 & 875803.8 & 6.6172 & $<0.0002$ \\
\hline LDFD x UHD & 445795.8 & 49 & 9097.87 & 12.8598 & $<0.0002$ \\
\hline THSP x UHD & 217754.6 & 21 & 10369.27 & 7.3295 & $<0.0005$ \\
\hline SVI x UHD & 34248965 & 21 & 1630903 & 12.3224 & $<0.0001$ \\
\hline
\end{tabular}

Source: Authors.

The results of the images after the UHD treatment (Figure 6b) reveal a significant signal in the seeds treated with Sil12CH and Sil30CH. Both responded, respecively, to a larger and smaller seedling development in relation to all other treatments. Even so, Bry $6 \mathrm{CH}$ application showed the most random and unexplained variation, as if there were no visible signs of fractality in the image. In general, the LCFD signal does not predict which seed will improve or worsen after HUD application when generated by BSL image.

The speckle caused by seed surface laser scattering - BSL (Rabal et al., 2018) is quite different from the quasifractal cold plasma - GDV patterns (Korotkov et al., 2010). The particles presented in BSL images have very similar fractality pattern sizes and this also occurs in GDV but with larger scale format. These interpretative morphologies show that LCFD (BSL and GDV) also differ from each other, and between the UHD treatments shown earlier in Tables 1 and 3, as well as in Figure 6.

\subsection{Effect of UHD treatments on adzuki bean seed germination and germination predictions from GDV and BSL images}

Bray-Curtis similarity cluster analysis showed a high cophenetic correlation (between 0.876 and 0.9644 ). That proves the sensitivity of GDV images in capturing UHD activ- ity in plant biological systems prior to germination (Figure 7). Even with such diverse behaviors as the response variables (SVI, LCFD, and THSP), some nonlinearity assumptions can be considered here, widely debated in UDH and homeopathic research (Marques, Bonato \& Mourão, 2013). In this case, the effect of the treatment that best responded to the seeds Si12CH (Figure 7) and $\mathrm{Si} 6 \mathrm{CH}$ (Table 4), indicates that there was 
a correlation with the decrease in variance in the BSL-THSP method, and in this sense, it represents a good sensor of seed activity.

Figure 4. GDV images (2b) treated with the Fujii-RenyiEntropy algorithm (3a-3f) for the control group. The pattern of germinated (g) and non-germinated (ng) seeds may be noted due to continuity or discontinuity (rupture) in the plasma line near the micropyle region (mr). To the right are the mean pixel intensities (gray value) for the seed sample analyzed.

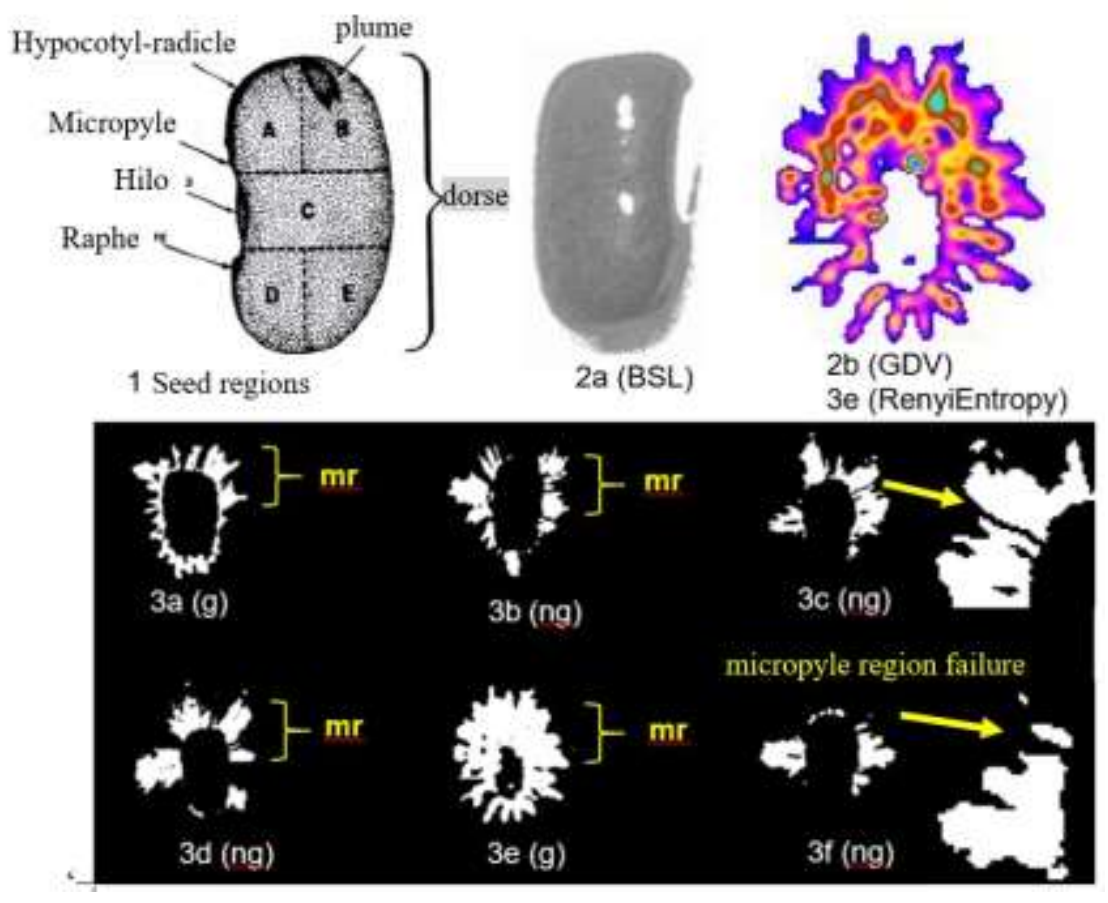

Source: Authors.

The classification of images obtained through the GDV and BSL scanner can cover several methods. The correlation between the images and the germination result can be done basically in three different ways: i) numerical (Arizaga et al., 1999; Karperien et al., 2011); ii) graphics (Fujii et al, 1987) and iii) frequencies (Minkin \& Nikolaenko, 2008). Even within these examples there is a wide range of methods. However, when generating the images, even if the method is not chosen, the generated images allow a first approximation of the problem with visible morphological differences (Figure 4), in this case, more appropriate to the GDV.

The total seedling area (TSA) variable was useful for comparing the treatments and helped in the visualization of the radicle, the hypocotyl and the epicotyl (Figures 4a-e and Table 4). In that perspective the difference between the treatments was significant and Si12CHand Bry30CH presented similar effects and higher seedling vigor compared to the others.

The morphology of germinated seedlings responded to treatments (HUD and wa- ter) and presented some significant statistical differences (Table 4). Among them, the treatment with Silicea $30 \mathrm{CH}$ decreased the seedling vigor, showing the smallest total seedling area $\left(44.78 \mathrm{~mm}^{2}\right)$, followed by the control treatments - A5 $\left(121.475 \mathrm{~mm}^{2}\right)$. All other treatments were superior.

The product of total seedling length (TSL) measurements with germination percent- age (\%) were highly correlated to total seedling area in $\mathrm{mm}^{2}$. The average of germination percentage (96.8\%), as well as the average of seedling length (208.97 $\mathrm{mm}$ ), influenced the vigor, according to the UHD and the dynamization potency. Silicea terra $6 \mathrm{CH}$ treat- ment showed higher 
seedling area and SVI measurements, but not enough to explain the differences between the other treatments (Figure 7 and Table 4).

The probable superiority of Bryonia $12 \mathrm{CH}$ treatment, perhaps, is justified by the benefits to the photosynthetic process, revealed in the seedling vigor improvement, even with nonlinear effects argued by some authors [29]. If we compare the results in Table 4 and the cluster in Figure 5a, it is observed that in certain UHDs, the biophotonics (GDV or BSL) was not sufficient to indicate which seeds or seed groups would germinate best. In any case, the information described in Table 1 highlights a good correlation between germination, UHD treatments and predictive biophotonic methods.

With the available capture tools (GDV and BSL) and image analysis, observed dif- ferences between the effects of UHD treatments would support studies of the intrinsic mechanisms of these substances in the seeds. Sucussed ultra dilutions partly explain similarities to specific instructional loads in plant cells in their unique characteristics, when compared to autonomous intelligent units (Silva et al., 2012).

Table 4. Tukey test with the original data replaced in place of the transformed data for the mean area of seedlings of adzuki-bean. Lages, SC, BraZil. Font: Author (2021)

\begin{tabular}{lccccr}
\hline Treatment & SG (\%) & TSL (mm) & SVI (index) & TSA $\left(\mathrm{mm}^{2}\right)$ & Difference \\
\hline Water 100\% & 96.1 & 124.53 & 11967.33 & 149.84 & $\mathrm{~d}$ \\
\hline Water 5\% alcohol & 95.6 & 100.32 & 9590,59 & 121.47 & $\mathrm{~d}$ \\
\hline Water 06 CH & 97.6 & 202.94 & 19806.94 & 218.04 & $\mathrm{c}$ \\
\hline Water 12 CH & 97.1 & 224.10 & 21760.11 & 258.41 & abc \\
\hline Water 30 CH & 97.9 & 278.09 & 27225.01 & 292.88 & abc \\
\hline Sil 30 CH & 90.4 & 35.79 & 3235.42 & 44.787 & $\mathrm{e}$ \\
\hline Sil 12 CH & 98.3 & 263.31 & 25883.37 & 285.69 & abc \\
\hline Sil 06 CH & 98.8 & 309.12 & 30541.06 & 336.59 & $\mathrm{a}$ \\
\hline Bry 30 CH & 98.7 & 292.29 & 28849.02 & 311.52 & $\mathrm{ab}$ \\
\hline Bry 12 CH & 97.7 & 259.66 & 25368.78 & 275.88 & $\mathrm{abc}$ \\
\hline Bry 06 CH & 96.8 & 208.52 & 20184.73 & 251.13 & $\mathrm{bc}$ \\
\hline
\end{tabular}

Note of Table 4: SMD $=10.884 \sqrt{1 / n_{1}-n_{2}}=$ significant minimum difference; $n_{1}$ and $n_{2}$ are the repetition numbers of two compared means; $n$ is the number of treatment repetitions. $\mathrm{SS}=65.16, \mathrm{MS}=6.51, p$-value $=7.04 \times 10^{-125}, \omega^{2}=0.4149$. SG $=$ seed germination $(\%)$; TSL $=\mathrm{Total} \mathrm{Seedling}$ Length $(\mathrm{mm}) ; \mathrm{TSA}=$ Total Seedling area $\left(\mathrm{mm}^{2}\right)$ and SVI $=$ Seed Vigor Index $=$ SG $(\%) \times$ TSL $(\mathrm{mm})$; The averages followed by the same letter do not differ statistically from each other. Levene's test for homoscedasticity was applied, based on the means: $p$ (equal) $=0.242$ and Welch's $\mathrm{F}$ test, in the case of unequal variances: $\mathrm{F}=83.98$, $\mathrm{df}=443.8, p=8.746 \times 10^{-96}$. The sum of squares between treatments (SS); Middle Square (MS); Snedecor coefficient $(\mathrm{F})$, probability $(p<0.001)$; The omega squared is a measure of effect size, ranging from 0 to $1: \omega^{2}=\left(\mathrm{SS}_{\mathrm{bg}}-\mathrm{dfb}_{\mathrm{g}} \mathrm{MS}_{\mathrm{wg}}\right) /\left(\mathrm{SS}_{\text {total }}+\right.$ $\mathrm{MS}_{\mathrm{wg}}$ ), where, bg = between groups; wg = within groups; $\mathrm{df}=$ degrees of freedom. Source: Authors.

In Figure 5, it is possible to observe a pattern in the THSP signals before seed germination. The same situation was observed when applying LCFD to the images generated by laser, before after treating the seeds with UHD (Figure 6). This result is extremely interesting for the choice of seeds that could participate in a laboratory test or even in the field. Although this was not the main objective of this research, it showed an important result that can be used in future research. 
Figure 5. Sample of THSP signal applied to the biospeckle laser (BSL) imaging method and results for germinated $(g)$ and non-germinated seeds $(n g)$, related to Figure $5 \mathrm{a}$ and $5 \mathrm{~b}$, respectively.

\section{THSP (Pixels Intensity)}

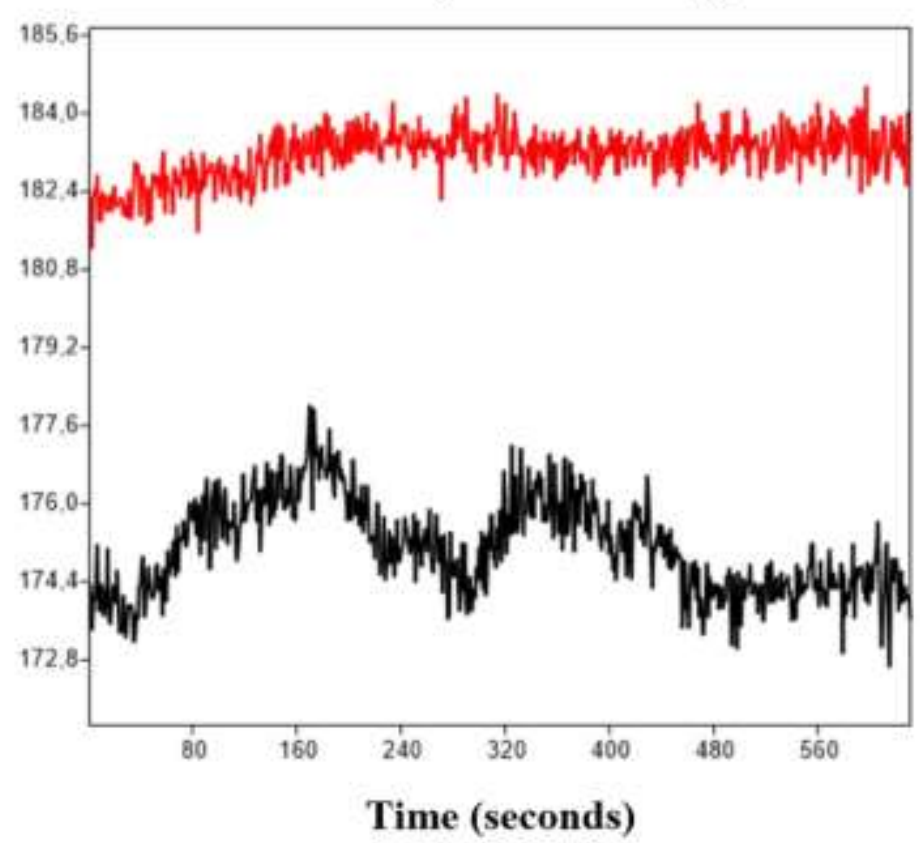

Source: Authors. 5a (g)

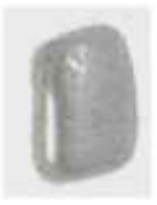

5b (ng)

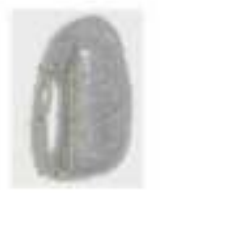

Another option would be to demonstrate the "singularity" that UHDs cause in seeds, perhaps something proportional to a resonance between specific regions of cells or plant tissue. Understanding the biochemical or metabolic signals and responses in plants can serve as a model that allows a better comprise of the physiological effects. Like a single system, plant organs are associated with different tissues, cells and metabolic reactions, functioning by transferring specific information, whose processes may vary according to the "trigger", in which case UHDs have this purpose (Waisse, 2019).

There were significant differences in the effect of UHD before and after seed treatment, observed with the numerical method LCFD in the images generated by laser (Figure 6). The seeds suffered more effect when treated with Sil 30 and $12 \mathrm{CH}$ and Bry $30 \mathrm{CH}$, this also corroborates the results of germination (SVI), shown in Table 4. Considering the numerical method used, the speckle laser showed a measurable fractability with LCFD. 
Figure 6. The observed frequencies of the averages of four replicates of 24 seeds for the LCFD variable generated by BLS in seed images in seeds treated with UHD, before (a) and after germinations (b) (Water $=$ Control; Bry = Bryonia: 6,12 and 30 and $\mathrm{Si}=$ Silice $:$ : 12 and 30CH).

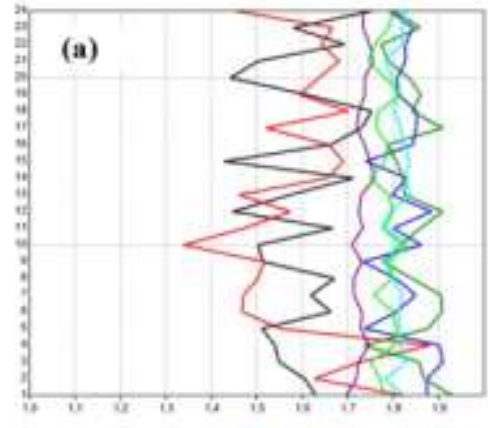

Grouping Information Using Fisher's LSD Method and 95\% Confidence for LCFD average before and after germination

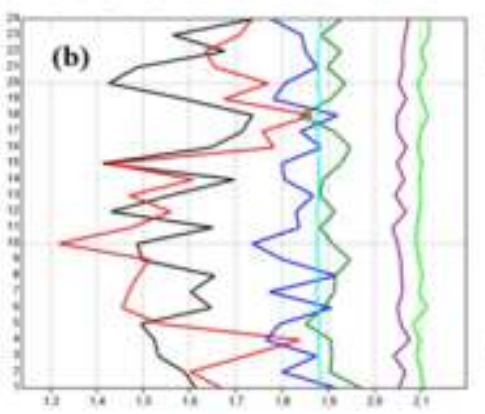

\begin{tabular}{|c|c|c|}
\hline \multicolumn{3}{|c|}{ LCFD means, UHD and Grouping (Letters) } \\
\hline $\mathbf{N}$ & Before germin: & ation \\
\hline 24 & I8.841 (B30) & A \\
\hline 24 & $1,8274(\mathrm{~B} 12)$ & A \\
\hline 24 & $1.8107(\mathrm{~B} 6)$ & $\mathrm{AB}$ \\
\hline 24 & $1,7831(\mathrm{~S} 30)$ & B \\
\hline 24 & $1,7306(\mathrm{~S} 12)$ & $\mathrm{C}$ \\
\hline 24 & $1,5982(\mathrm{~W})$ & $\mathrm{D}$ \\
\hline 24 & $1.5961(\mathrm{~B} 6)$ & D \\
\hline \multicolumn{3}{|c|}{ After germination } \\
\hline 24 & $2,101(\mathrm{~S} 30) \mathrm{A}$ & \\
\hline 24 & $2,057(\mathrm{~S} 12)$ & B \\
\hline 24 & $1,908(\mathrm{~B} 30)$ & $\mathrm{C}$ \\
\hline 24 & $1,879(\mathrm{~S} 6)$ & C \\
\hline 24 & $1.834(\mathrm{~B} 12)$ & D \\
\hline 24 & $1,622(\mathrm{~B} 6)$ & $\mathrm{E}$ \\
\hline 24 & $1.582(W)$ & F \\
\hline
\end{tabular}

Means that do not share a letter are significantly different.

\section{Local Connected Fractal Dimension Frequencies (LCFD)}

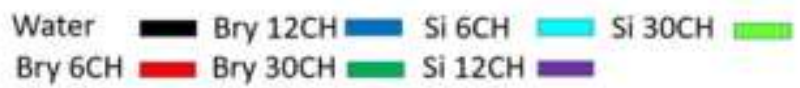

Source: Authors.

To generate the results in Figure 6, the seeds were treated prior to sprouting with homeopaties and water (control), after a time (reported in method) and BSL images were made. Soon after germination (radicle protrusion occurred in two days), BSL was again applied and the images were analyzed (LCFD). Thus, the efficiency of the system in capturing signals in the seeds was well proven. What is still unanswered is the origin of these signals (enzymatic-metabolic; temperature variations, etc). The Figure 7 shows clusters of these differences before the seeds germinate.

The result of UHD "visualization" of spatial activity, using BSL-LCFD, identifies signs of substantial increase in biospeckle activity (fractability of pixel intensity) before germination and it distinguishes seeds that had an effect with or without the application of UHDs (Figure 7). A similar fact was observed in the onset of early signs (biospeckle) of phytopathogenic infection in apples prior to the visual occurrence of the symptom (Pieczywek et al., 2018).

The self-similarity of the fractal system exists in the patterns of laser spots produced in a diffuse manner at $670 \mathrm{~nm}$ and spread reflectively on the azuki bean seed integument, forming a certain roughness (speckle laser). In this experiment, the fractal dimension and the lacunarity of the stain patterns (or speckle) are related to the surface roughness.

$\mathrm{Li}, \mathrm{Li}$, and Qiu (2016) analyzed different types of roughness and noticed that the fractal dimension decreases in logarithm while the roughness increases. But, on the other hand, the gap increases in logarithm along with the increase in roughness. This can indicate different behaviors according to the quality of the seed or the species analyzed.

When similar roughness occurs, the fractal dimension and lacunarity are different for different types of roughness, respectively. Therefore, the fractal dimension and the lacunarity treated with the LCFD numerical method can be used as new 
characteristic parameters to determine the surface roughness. This fractal method, according to $\mathrm{Li}$, $\mathrm{Li}$, and Qiu (2016), can also be developed to be a non-invasive detection of optical properties of spreading media, such as biological tissue.

Silicea terra $12 \mathrm{CH}$ and Bryonia alba 30CH treatments, significantly different from the GDV and BSL images studied in this research attempted to predict the viability and vigor of seeds under UHD effect and they were able to recognize clusters related to the LCFD method (cluster analysis of Figure 7). They showed the best effect for control treatment, water (W).

Figure 7. Multivariate cluster for each and numerical method for image analysis, as well as their relationship to UHD treatments after germination. Paired group, Bray-Curtis's similarity measure: SVI-UHD Coph. Corr. Coeff.: 0.95; GDV- LCFD Coph. Corr. Coeff.: 0.96; BSL-LCFD Coph. Corr. Coeff.: 0.92; BSL-THSP Coph. Corr. Coeff.: 0.97. Note: abbreviations to be modified: W100 (water 100\%); W5 (water with 5\% alcohol); S (Silicea) and B (Bryonia).

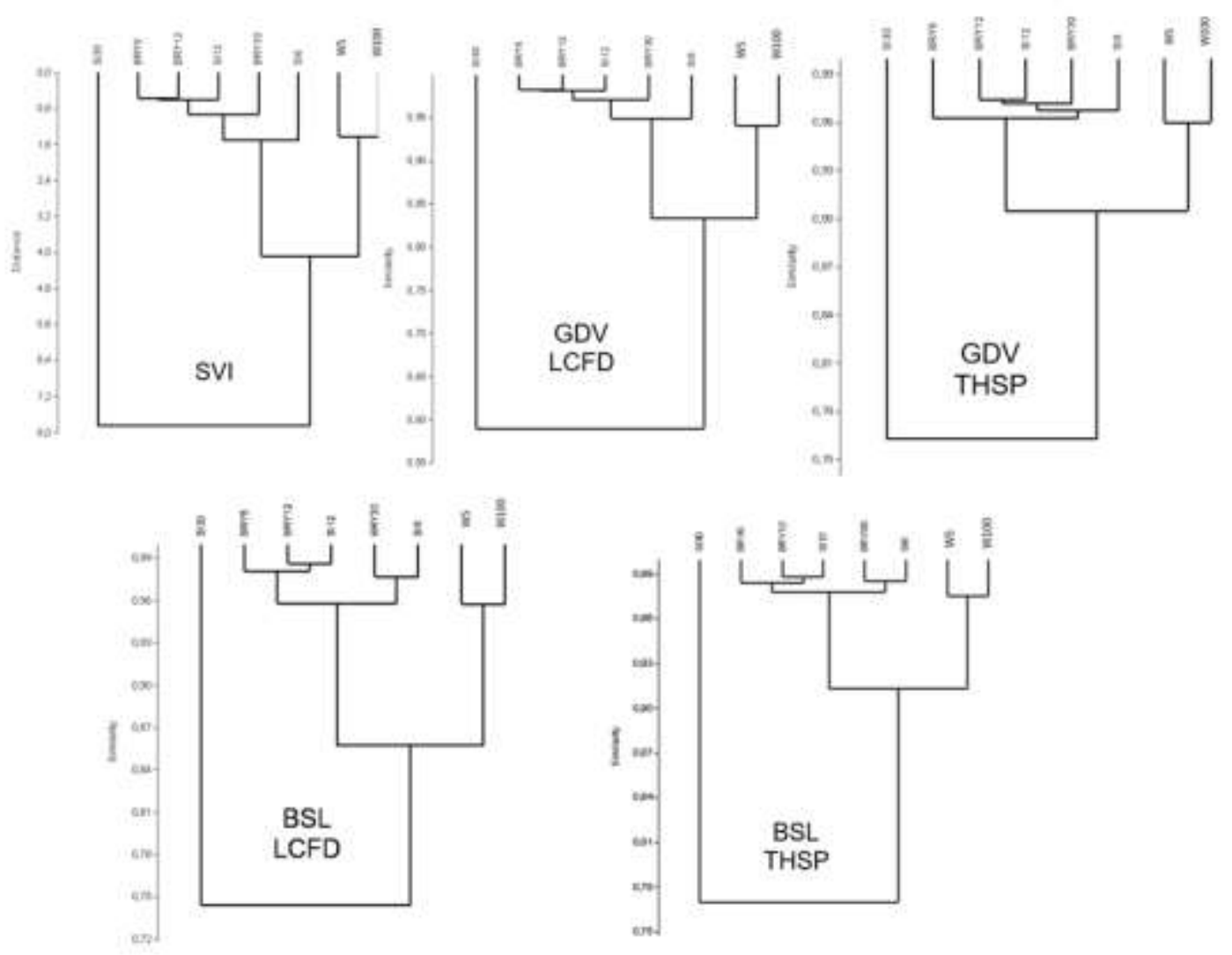

Source: Authors.

Therefore, the non-application of UHD (control, water) did not allow to classify viable seeds with $100 \%$ safety. Overall, the images generated by BSL-THSP were better for this identification compared to GDV as it was initially shown in Table 1. The cophenetic correlation coefficients (Hammer et a., 2019) for SVI clusters and other numerical methods were also significant, above $90 \%$, and the correlation between the pixel intensities in the images, associated with the effects of treatments that had the least effect on germination were more satisfactory than the others (Figure 7).

\section{Final Considerations}

The forecast of seed germination behavior was an important result when most conventional tests require at least 5 days to obtain the results on seed vigor. At the same time, the research was able to prove the existence of reactions in the seeds 
indicated by the presence of ultrahigh dilution at different potentization levels of substances. In the present study, BSL was slightly higher than GDV, obtaining an average of overall percentage of correct answers of 89\% against 87\% of GDV (Table 1).

Advantages to employ of laser and cold plasma are the lower technological cost, the simplicity of the experimental setup and the shorter post-processing time of the images. In all these respects, BSL-THSP was superior to GDV-THSP and GDV-LCFD. But when analyzed from a technical perspective, GDV-LCFD was not significantly different from the use of BSL-LCFD.

The innovation in this research was to compare the two devices and potential of these technologies to identify signs of drugs in the azuki beans seeds, and to know in advance the effect on seedlings.

In a perspective for the coming years, the technologies presented in this research may be used to improve germination tests; making the choice of medicines in plants more efficient before carrying out larger and expensive experiments; make it easier for germplasm banks to test their rare seeds before conducting a conventional germination test and, not exhausting the possibilities, as they are low-cost technologies, expand their use to agricultural communities with less purchasing power.

\section{Acknowledgments}

To FAPESC through the project Rede Guarani Serra Geral/TO 2015TR1067.

\section{References}

Arizaga, R., Trivi, M. \& Rabal. (1999). Speckle time evolution characterization by the co-occurrence matrix analysis. Optics \& Laser Technology 31, 163-9. https://doi.org/10.1016/S0030-3992(99)00033-X

Bajpai, R., Bajpai, P. \& Roy, D. (1991). Ultraweak photon emission in germinating seeds: a signal of biological order. Journal of bioluminescence and chemiluminescence 6, 227-30. https://doi.org/10.1002/bio.1170060403

Betti, L., Trebbi, G., Kokornaczyk, M.O., Nani, D., Peruzzi, M., Dinelli, G., Bellavite, P. \& Brizzi, M. (2017). Number of succussion strokes affects effectiveness of ultra-high- diluted arsenic on in vitro wheat germination and polycrystalline structures obtained by droplet evaporation method. Homeopathy 26, 47-54. https://doi.org/10.1016/j.homp.2016.12.001

Bonfim, F., Casali, V., Mendonca, E. \& Martins, E. (2012). Estresse hídrico em feijoeiro (Phaseolus vulgares L.) tratado com os preparados homeopáticos de Arnica montana. Enciclopédia biosfera 8, 530-8.

Braga, R. A., Enes, A. M., Miron, D., Rabelo, G. F., J. Barreto Filho, B. \& Horgan, G. W. (2007). Biological feature isolation by wavelets in biospeckle laser images. Computers and electronics in agriculture 58, 123-32. https://doi.org/10.1016/j.compag.2007.03.009

Braga, R. A., Rivera, F.P. \& Moreira, J. (2016). A practical guide to Biospecle Laser analysis: theory and Software. Ed. UFLA.

Deekshitulu, B. P. (2019). Impact of Homeopathy in Agriculture. Global Journal of Energy and Environment 1, 2. Review Article.

Elias, S. G., Copeland, L. O., McDonald, M. B. \& Baalbaki, R. Z. (2012). Seed testing: principles and practices. Michigan State University Press.

Fujii, H., Nohira, K., Yamamoto, Y., Ikawa, H. \& Ohura, T. (1987). Evaluation of blood flow by laser speckle image sensing. Part 1. Applied Optics 26, 5321-5. https://doi.org/10.1364/AO.26.005321

Hammer, Ø., Harper, D. \& Ryan, P. (2019). PAST: paleontological statistics. Version 3.25. National History Museum, University of Oslo.

Karperien, A., Jelinek, H., Milosevic, N. \& Cracow, P. (2011, June). Reviewing lacunarity analysis and classification of microglia in neuroscience. Proceedings of the 8th European Conference on Mathematical and Theoretical Biology European Society for Mathematical and Theoretical Biology (ESMTB) 2011 MS\#88. DOI: 10.13140/2.1.3576.6082.

Kokornaczyk, M. O., Trebbi, G., Dinelli, G., Marotti, I., Bregola, V., Nani, D., Borghini, F. \& Betti, L. (2014). Droplet evaporation method as a new potential approach for highlighting the effectiveness of ultrahigh dilutions. Complementary therapies in medicine 22 , 333-40. https://doi.org/10.1016/j.ctim.2014.02.005

Kononenko, I., Bevk, M., Sadikov, S. \& Sajn, L. (2004). Classification of different types of coronas using parametrization of images and machine learning. In: Konstantin G. Korotkov (Ed.). Measuring Energy Fields: Current Research. - Backbone Publishing Co. Fair Lawn, USA, pp. 193-208.

Korotkov, K. Measuring Energy Fields: State of the Science, Backbone Publishing, Fair Lawn, USA. pp. $278,2004$.

Korotkov, K. G., Matravers, P., Orlov, D. V. \& Williams, B. O. (2010). Application of electrophoton capture (EPC) analysis based on gas discharge visualization (GDV) technique in medicine: a systematic review. The Journal of Alternative and Complementary Medicine 16, $13-25$. 
Li, H., Li, Z. \& Qiu, Y. (2006). Fractal analysis of laser speckle for measuring roughness. ICO20: Optical Information Processing, edited by Yunlong Sheng, Songlin Zhuang, Yimo Zhang, Proc. of SPIE Vol. 6027, 60271S, 0277-786X/06/\$15. https://doi.org/10.1117/12.668182

Marques, R. M., Bonato, C. M. \& Mourão, K. S. M. (2013). Effect of homeopathic drug Bryonia alba on oxygen uptake by alternative oxidase pathway in soybean. in II International Conference on Homeopathy in Agriculture. pp 4.

Matzrafi, M., Herrmann, I., Nansen, C., Kliper1, T., Zait, Y., Ignat, T., Siso, D., Rubin, B., Karnieli, A. \& Eizenberg, H. (2017). Hyperspectral technologies for assessing seed germination and trifloxysulfuron-methyl response in Amaranthus palmeri (Palmer Amaranth). Frontiers in plant science 8, 474. https://doi.org/10.3389/fpls.2017.00474

Ministério da Agricultura, Pecuária e Abastecimento. (2009). Regras para análise de sementes. Ministério da Agricultura, Pecuária e Abastecimento. Brasília. Mapa/ACS, 2009. 399 p.

Ministério da Agricultura, Pecuária e Abastecimento. (2014). Instrução Normativa No 17 , de 18 de junho de 2014 . Ministério da Agricultura, Pecuária e Abastecimento. Secretaria de Defesa Agropecuária. Http://www.agricultura.gov.br/assuntos/sustentabilidade/organicos/legislacao/portugues/instrucaonormativa-no-17-de-18-de-junho-de-2014.pdf. [Online].

Minkin, V. A. \& Nikolaenko, N. N. (2008). Application of Vibraimage technology and system for analysis of motor activity and study of functional state of the human body. Biomedical Engineering. St Petersburg, 42(4), 1296-200. https://doi.org/10.1007/s10527-008-9045-9

Orjales, I., López-Alonso, M., Rodríguez-Bermúdez, R., Rey-Crespo, F., Villar, A. \& Miranda, M. (2016). Use of homeopathy in organic dairy farming in Spain. Homeopathy 105, 102-8. https://doi.org/10.1016/j.homp.2015.08.005

Panda, S. S., Mohanty, S. S. \& Dhal, N. K. (2013). Effects of potentized homeopathic medicines on the germination, growth and photosynthetic activity of Pisum sativum L. Recent research in Science and Technology 5, 11-14.

Pieczywek, P., Cybulska, J., Szymańska-Chargot, M., Siedliska, A., Zdunek. A., Nosalewicz, A., Baranowski, P. \& Kurenda, A. (2018). Early detection of fungal infection of stored apple fruit with optical sensors-Comparison of biospeckle, hyperspectral imaging and chlorophyll fluorescence. Food control 85, 327-38. https://doi.org/10.1016/j.foodcont.2017.10.013

Rabal, H., Grumel, E., Cap, N., Buffarini, L. \& Trivi, M. (2018). A descriptor of speckle textures using box fractal dimension curve. Optics and Lasers in Engineering 106, 47-55. https://doi.org/10.1016/j.optlaseng.2018.02.006

Rabelo, G. F., Enes, A. M., Junior, R. A. B. \& Fabbro, I. M. Dall. (2011). Frequency response of biospeckle laser images of bean seeds contaminated by fungi. Biosystems engineering 110, 297-301. https://doi.org/10.1016/j.biosystemseng.2011.09.002

Riva, N. da, Donato, G., Kagami, F. L., Marques, R. M., Bonato, C. M. \& Mourão, K. S. M. (2013, September). Effect of homeopathic drug Bryonia alba on respiration of embryo and root apices in Glycine max L. Merrill. cv. BRS 232. Annals of International II Conference on Homeopathy in Agriculture, Maringá, PR, Brazil.

Sahoo, P. K. \& Arora, G. (2004). A thresholding method based on two-dimensional Renyi's entropy. Pattern Recognition 37, 1149-61. https://doi.org/10.1016/j.patcog.2003.10.008

Schulte, J. \& Endler, P. C. (2015). Update on preliminary elements of a theory of ultra high dilutions. Homeopathy 104, 337-42. https://doi.org/10.1016/j.homp.2015.09.010

Shtam, A. I., Minkin, V. A. \& Korotkov, K. G. (1997). Dispositivo para visualização de imagem por descarga de gás. Patente BR9714982A.1997.

Silva, H. A da, Parizotto, A. V., Moreira, F. C., Marques, R. A., Reis, B., \& Bonato, C. M. (2012). The effect of high dilutions of Pulsatilla nigricans on the vigour of soybean seeds subjected to accelerated aging. Acta Scientiarum. Agronomy, 34(2), 201-206. https://doi.org/10.4025/actasciagron.v34i2.13043

Singhania, A., \& Singhania, P. K. (2014). Homoeopathy in agriculture. Building Organic Bridges 2,667-70. https://doi.org/10.3220/REP_20_1_2014

Sutton, D. B. \& Punja, Z. K. (2017). Investigating biospeckle laser analysis as a diagnostic method to assess sprouting damage in wheat seeds. Computers and Electronics in Agriculture 141, 238-47. https://doi.org/10.1016/j.compag.2017.07.027

Thomas, Y. (2015). From high dilutions to digital biology: the physical nature of the biological signal. Homeopathy 104, 295-300. https://doi.org/10.1016/j.homp.2015.06.008

Waisse, S., \& Bonamin, L. B. (2019). Explanatory models for homeopathy part 2: state of art. Transdisciplinarity and Translationality in High Dilution Research. Signals and Images GIRI Series, Ed Leoni Bonamin \& S. Waisse. Cambridge Scholars Publishing, 26-43. 